\title{
Can Sepsis Be Detected in the Nursing Home Prior to the Need for Hospital Transfer?
}

\author{
Philip D. Sloane MD, MPH ${ }^{\text {a,b,c,*, Kimberly Ward BA }}{ }^{\text {a }}$, David J. Weber MD, MPH ${ }^{\text {c,d }}$, \\ Christine E. Kistler MD, MASc ${ }^{\mathrm{a}, \mathrm{b}}$, Benjamin Brown $\mathrm{BS}^{\mathrm{c}}$, Katherine Davis $\mathrm{BS}^{\mathrm{c}}$, \\ Sheryl Zimmerman $\mathrm{PhD}^{\mathrm{a}}$ e \\ ${ }^{a}$ Cecil G. Sheps Center for Health Services Research, University of North Carolina at Chapel Hill, Chapel Hill, NC \\ ${ }^{\mathrm{b}}$ Department of Family Medicine, University of North Carolina at Chapel Hill, Chapel Hill, NC \\ ${ }^{\mathrm{c}}$ School of Medicine, University of North Carolina at Chapel Hill, Chapel Hill, NC \\ ${ }^{\mathrm{d}}$ Department of Medicine, University of North Carolina at Chapel Hill, Chapel Hill, NC \\ e School of Social Work, University of North Carolina at Chapel Hill, Chapel Hill, NC
}

\section{A B S T R A C T}

Keywords:

Nursing homes

infection

sepsis

diagnosis

\begin{abstract}
Objectives: To determine whether and to what extent simple screening tools might identify nursing home $(\mathrm{NH})$ residents who are at high risk of becoming septic.

Design: Retrospective chart audit of all residents who had been hospitalized and returned to participating NHs during the study period.

Setting and Participants: A total of $236 \mathrm{NH}$ residents, 59 of whom returned from hospitals with a diagnosis of sepsis and 177 who had nonsepsis discharge diagnoses, from 31 community NHs that are typical of US nursing homes overall.

Measures: NH documentation of vital signs, mental status change, and medical provider visits $0-12$ and 13-72 hours prior to the hospitalization. The specificity and sensitivity of 5 screening tools were evaluated for their ability to detect residents with incipient sepsis during 0-12 and 13-72 hours prior to hospitalization: The Systemic Inflammatory Response Syndrome criteria, the quick Sequential Organ Failure Assessment (SOFA), the 100-100-100 Early Detection Tool, and temperature thresholds of $99.0^{\circ} \mathrm{F}$ and $100.2^{\circ} \mathrm{F}$. In addition, to validate the hospital diagnosis of sepsis, hospital discharge records in the NHs were audited to calculate SOFA scores.

Results: Documentation of 1 or more vital signs was absent in $26 \%-34 \%$ of cases. Among persons with complete vital sign documentation, during the 12 hours prior to hospitalization, the most sensitive screening tools were the $100-100-100$ Criteria $(79 \%)$ and an oral temperature $>99.0^{\circ} \mathrm{F}(51 \%)$; and the most specific tools being a temperature $>100.2^{\circ} \mathrm{F}(93 \%)$, the quick SOFA $(88 \%)$, the Systemic Inflammatory Response Syndrome criteria (86\%), and a temperature $>99.0^{\circ} \mathrm{F}(85 \%)$. Many SOFA data points were missing from the record; in spite of this, $65 \%$ of cases met criteria for sepsis.

Conclusions: NHs need better systems to monitor NH residents whose status is changing, and to present that information to medical providers in real time, either through rapid medical response programs or telemetry.
\end{abstract}

Sepsis is a major source of morbidity and mortality among the nation's estimated 1.4 million nursing home $(\mathrm{NH})$ residents. ${ }^{1}$ In the emergency department, $\mathrm{NH}$ residents are 17 times more likely to be

\footnotetext{
Supported by research grant R18 HS022846-01 from the US Agency for Healthcare Research and Quality.

The authors declare no conflicts of interest.

* Address correspondence to Philip D. Sloane MD, MPH, Department of Family

Medicine, University of North Carolina at Chapel Hill, Chapel Hill, NC 27599.

E-mail address: Philip_Sloane@med.unc.edu (P.D. Sloane).
}

diagnosed with sepsis than non-NH residents, such that nearly $4 \%$ of emergency department visits among $\mathrm{NH}$ residents include a diagnosis of sepsis. ${ }^{2}$ Furthermore, when sepsis occurs, it is more likely to be severe if the patient is a $\mathrm{NH}$ resident, leading to higher rates of intensive care unit admission, longer hospital stays, and higher mortality rates when compared to non-NH residents. ${ }^{3-5}$ Moreover, older adults who survive sepsis are at increased risk of new or worsening cognitive impairment and functional decline when compared with nonsepsis admissions. ${ }^{6}$ The prominence of sepsis in this setting highlights the importance of early identification and 
effective management of $\mathrm{NH}$ residents who are at high risk of becoming septic.

Because early diagnosis and treatment can reduce morbidity, several screening tools for early sepsis have been developed. A longestablished tool is the Systemic Inflammatory Response Syndrome (SIRS) criteria. In the setting of suspected infection, SIRS criteria are met if 2 or more of the following are present: body temperature $>38^{\circ} \mathrm{C}$ or $<36^{\circ} \mathrm{C}$, heart rate $>90 \mathrm{bpm}$, respiratory rate $>20$ breaths/min or $\mathrm{PaCO}_{2}<32 \mathrm{~mm} \mathrm{Hg}$, or white blood cell count $>12,000$ or $<4000$ cells/ microliter. ${ }^{7}$ Despite the fact that studies indicated that the SIRS criteria had only moderate sensitivity and low specificity, ${ }^{8}$ they were incorporated directly into "sepsis initiation bundles" of many hospitals participating in the international Surviving Sepsis campaign. ${ }^{9}$ Concomitant with the focus on early detection and treatment of sepsis was a nearly $300 \%$ rise in hospital sepsis diagnoses between 2003 and 2011, leading to concern that sepsis was being overdiagnosed in emergency departments and hospitals. ${ }^{10}$

To address this issue, a combined task force of the Society of Critical Care Medicine and the European Society of Intensive Care Medicine convened in 2014 to evaluate and update the definitions of sepsis and septic shock. This effort led to the development of the Sequential Organ Failure Assessment (SOFA) score as a diagnostic criterion for sepsis, ${ }^{11,12}$ and the quick SOFA, or qSOFA, as a sepsis screening tool that requires no laboratory tests. In the setting of suspected infection, qSOFA criteria are met if the patient has 2 or more of the following: respiratory rate $\geq 22 / \mathrm{min}$, altered mentation [Glasgow Coma Scale $(\mathrm{GCS})<15$ ], or systolic blood pressure $\leq 100 \mathrm{~mm} \mathrm{Hg}{ }^{11} \mathrm{~A}$ third tool, the 100-100-100 Early Detection Tool, has been recommended by the Minnesota Hospital Association as a screening triage tool for sepsis in long-term care. ${ }^{13,14}$ In patients with suspected infection, the 100-100-100 criteria are met if 2 or more of the following are present: temperature $>100^{\circ} \mathrm{F}$, heart rate $>100 \mathrm{bpm}$, and systolic blood pressure $<100 \mathrm{~mm} \mathrm{Hg}$. 13,14

Unfortunately, little is known about the prehospital course of $\mathrm{NH}$ residents and the performance of the above screening tools. Indeed, published studies of $\mathrm{NH}$ sepsis have exclusively relied on emergency department and hospital data, and none have reviewed $\mathrm{NH}$ records. $^{2-5,15-21}$ Thus, there is a dearth of published studies that have investigated the pre-admission status of $\mathrm{NH}$ residents who were subsequently hospitalized with a diagnosis of sepsis. As a result, it is unclear whether and to what extent signs are present in the days prior to hospitalization that could have allowed NH staff to identify and treat early sepsis, thereby improving overall morbidity and mortality.

To better understand the potential for earlier diagnosis of sepsis in the $\mathrm{NH}$ setting, we audited the records of $236 \mathrm{NH}$ residents who had been hospitalized and returned to the $\mathrm{NH}, 59$ whose hospital discharge diagnoses included sepsis and 177 whose discharge diagnoses did not. Data collection included demographic elements, vital signs, treatment data from $\leq 12$ hours and 13-72 hours prior to hospitalization, and SOFA elements from the hospital discharge summaries. Our goal was to determine whether and to what extent the qSOFA, the SIRS criteria, the 100-100-100 Early Detection Tool, and the presence or absence of fever might have differentiated early sepsis from other evolving acute conditions.

\section{Methods}

\section{Setting and Study Population}

We recruited 31 community NHs in North Carolina to participate in a study of infection management. To help obtain $\mathrm{NH}$ buy-in, potential sites were identified through either a for-profit regional $\mathrm{NH}$ chain or a long-term care medical practice. A total of $35 \mathrm{NHs}$ were approached for participation; 4 refused and 31 (86\%) agreed to participate. The mean $\mathrm{NH}$ bed size was $113 ; 81 \%$ were for-profit; the mean occupancy rate was $87 \%$; licensed nurses and certified nursing assistants were staffed at an average rate of 1.5 and 2.2 hours, respectively, per resident; and the mean quality rating on Nursing Home Compare was 3.3. None of these mean characteristics differ statistically from all NHs nationally. ${ }^{22}$

\section{Measures and Data Collection}

Within each $\mathrm{NH}, 2$ data collection site visits were conducted. The first data visits were between November 2014 and March 2015 and included all 31 homes; the second visits were between December 2015 and April 2016 and included 27 homes (the others had withdrawn from the study by that time). At each visit, trained research assistants identified and audited all cases in which patients had been hospitalized and returned to the $\mathrm{NH}$ in the month prior to that data collection visit. Cases that did not return to the $\mathrm{NH}$ ( $20 \%$ of admissions) were excluded from the study because hospital discharge summaries were unavailable.

Each individual case's medical and nursing records were systematically audited to record signs and symptoms during 2 time periods: 0-12 and 13-72 hours prior to hospitalization. Data recorded included vital signs, visits by medical providers, and actions taken. Data were also recorded on each patient's age and sex, and whether they had been hospitalized in the 30 days prior to this hospitalization.

To help identify whether and to what extent sepsis may have been overdiagnosed, hospital discharge records available in the $\mathrm{NH}$ were audited to identify or calculate the following SOFA indicators: $\mathrm{PaO}_{2}$ / $\mathrm{FiO}_{2}$, platelet count, bilirubin, mean arterial pressure, mental status impairment, and serum creatinine. ${ }^{11}$ We did not expect many, if any, $\mathrm{NH}$ staff to record the GCS, as recommended in determining the qSOFA, so we also audited for any indication of alteration in mental status from baseline. Urine output, an additional measure of kidney dysfunction (beyond serum creatinine) in the SOFA scale, was not collected, as it was rarely if ever included in hospital discharge summaries.

Study methods and measures were approved by the Institutional Review Board of the University of North Carolina at Chapel Hill.

\section{Statistical Analysis}

Analyses included descriptive statistics. The 2 study samples (admissions with a sepsis diagnosis and those without) were compared using 2-tailed $\chi^{2}$ statistic or the Student $t$-test, as appropriate, and calculated using SAS v 9.4 (SAS Institute, Cary, NC). ${ }^{23}$ Data available from the NH record were used to estimate the proportion of cases with a sepsis diagnosis who met SOFA criteria for sepsis. To adjust for difference in the method of measuring temperature, we subtracted $0.75^{\circ} \mathrm{F}$ from rectal and tympanic readings and added $0.75^{\circ} \mathrm{F}$ to axillary readings to estimate an oral temperature equivalent. ${ }^{24}$

The sensitivity and specificity of the SIRS, qSOFA, and 100-100-100 criteria were calculated by comparing positive rates in the sepsis sample with the rates for the nonsepsis sample. Using the same method, we also calculated the sensitivity and specificity of a temperature $\geq 99.0^{\circ} \mathrm{F}$ and a temperature $\geq 100.2^{\circ} \mathrm{F}^{25,26}$

\section{Results}

Table 1 displays demographic data, infection diagnoses in the hospital, and the clinical status in the 72 hours prior to hospitalization for the 59 sepsis and 177 nonsepsis cases. No significant difference was noted between age, sex, or prior hospitalization status of the 2 groups. One-half of the nonsepsis sample had a discharge diagnosis that included 1 or more infections, and $46 \%$ were returned to the $\mathrm{NH}$ on antibiotics, compared with $75 \%$ of the sepsis group. 
Table 1

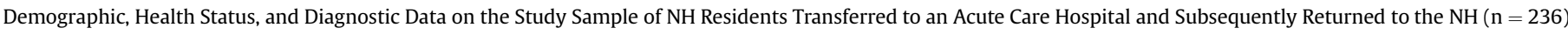

\begin{tabular}{|c|c|c|c|}
\hline \multirow[t]{2}{*}{ Variables } & \multicolumn{2}{|c|}{$\begin{array}{l}\text { Discharge Diagnosis Includes Sepsis? } \\
\text { Mean (SD) or N (\%) }\end{array}$} & \multirow[t]{2}{*}{$P$ Value for Difference ${ }^{\dagger}$} \\
\hline & Yes $(n=59)^{*}$ & No $(n=177)^{*}$ & \\
\hline Age, y & $78.4(12.2)$ & $79.9(11.6)$ & .41 \\
\hline Sex: Male & $27(46)$ & $65(37)$ & .23 \\
\hline Prior hospitalization $\leq 30 \mathrm{~d}$ beforehand & $19(32)$ & $74(42)$ & .19 \\
\hline Discharge diagnosis: a. pneumonia & $21(36)$ & $46(26)$ & .16 \\
\hline b. other respiratory infection & $2(3)$ & $4(2)$ & .46 \\
\hline c. Urinary tract infection & $30(51)$ & $44(25)$ & $<.001$ \\
\hline d. skin/soft tissue infection & $5(8)$ & $10(6)$ & .31 \\
\hline e. no infection & $0(0)$ & $89(50)$ & $<.001$ \\
\hline Patient returned to $\mathrm{NH}$ on antibiotics & $44(75)$ & $81(46)$ & $<.001$ \\
\hline \multicolumn{4}{|c|}{ Clinical status documentation $13-72 \mathrm{~h}$ before transfer } \\
\hline Temperature documented & $46(78)$ & $135(76)$ & .79 \\
\hline Heart rate documented & $44(75)$ & $134(76)$ & .86 \\
\hline Respiratory rate documented & $43(73)$ & $129(73)$ & .99 \\
\hline Systolic blood pressure documented & $44(75)$ & $135(76)$ & .79 \\
\hline All 4 of the above vital signs documented & $43(73)$ & $123(69)$ & .62 \\
\hline Acute mental status change documented & $5(8)$ & $9(5)$ & .17 \\
\hline Medical provider saw resident ${ }^{\ddagger}$ & $11(19)$ & $31(18)$ & .74 \\
\hline Antibiotic prescribed & $13(22)$ & $43(24)$ & .77 \\
\hline \multicolumn{4}{|c|}{ Clinical status documentation $\leq 12 \mathrm{~h}$ before transfer } \\
\hline Temperature documented & $47(80)$ & $142(80)$ & .93 \\
\hline Heart rate documented & $46(78)$ & $147(83)$ & .38 \\
\hline Respiratory rate documented & 41 (69) & $141(79)$ & .11 \\
\hline Systolic blood pressure documented & $44(75)$ & $144(81)$ & .26 \\
\hline All 4 of the above vital signs documented & $39(66)$ & $131(74)$ & .24 \\
\hline Acute mental status change documented & $22(37)$ & $40(23)$ & .08 \\
\hline Medical provider saw resident & $11(19)$ & $29(16)$ & .59 \\
\hline Antibiotic prescribed & $18(31)$ & $39(22)$ & .14 \\
\hline
\end{tabular}

*Sample sizes for selected variables were slightly reduced because of the lack of documentation.

'Determined by $\chi^{2}$ or $t$-test.

${ }^{\ddagger}$ Medical provider $=$ physician, nurse practitioner, or physician assistant.

Documentation of vital signs and cognitive status, and of medical provider visits to the resident prior to hospitalization is also displayed in Table 1. All 4 vital signs (temperature, pulse, respiratory rate, and blood pressure) were documented during the 12 hours prior to hospitalization in $66 \%$ of the sepsis cases and $74 \%$ of the nonsepsis cases; for 13-72 hours prior to hospitalization the corresponding numbers were $73 \%$ and $69 \%$ of cases, respectively. Documentation of a change in cognitive function, a requirement of the qSOFA, was virtually never done using the recommended tool, the GCS. ${ }^{27}$ Unstructured documentation of a mental status change was, however, present in $60 \%$ of cases, but no entries regarding a preservation of baseline mentation were noted. Documentation of a visit by a medical provider (physician, nurse practitioner, or physician assistant) in the 12 hours prior to hospital transfer was present in only $19 \%$ of the sepsis cases and $16 \%$ of the nonsepsis cases; during the 13-72 hours prior to transfer the corresponding figures were $19 \%$ and $18 \%$, respectively. No significant differences in clinical status documentation were noted between the 2 groups.

To estimate whether sepsis cases had been overdiagnosed in the hospital, we gathered what information on SOFA indicators was available in the hospital discharge summaries and, if available, admission notes, for the 54 study participants with "sepsis" as a discharge diagnosis and with an available discharge summary. Of the SOFA elements, $\mathrm{PaO} 2 / \mathrm{FiO}_{2}$ could be calculated on $56 \%$ of records, bilirubin was available in $44 \%$, mean arterial pressure in $80 \%$, platelet count in $96 \%$, and creatinine in $96 \%$. Three had documentation of having been treated with intravenous epinephrine or dopamine. GCS was only available in 1 chart (2\%); so, we allowed a statement of mental status impairment (60\% of cases) to substitute in estimating the SOFA. Despite the incompleteness of the data, 35 (65\%) of the 54 cases had a SOFA score $\geq 2$, which is the threshold for organ dysfunction required for a diagnosis of sepsis; 21 of these 30 (56\% of the sample) would have met SOFA criteria if "mental status impairment" was not allowed as a substitute for GCS. The appendix displays a table of the SOFA data from hospital records present in the study participants.

Table 2 describes the performance of the various screening tools in differentiating patients with impeding sepsis from those who would subsequently be hospitalized with a nonsepsis diagnosis, with analyses restricted to study participants for whom vital sign data were complete during 72 hours prior to hospitalization $(n=182 ; 73 \%$ of the sample). In the 13-72 hours prior to hospitalization, no tool had a

Table 2

Performance of Screening Tools in Distinguishing Patients Transferred From a NH to a Hospital With Early Sepsis From Patients Without Sepsis*

\begin{tabular}{|c|c|c|c|c|c|}
\hline \multirow[t]{2}{*}{$\begin{array}{l}\text { Sepsis Screening } \\
\text { Tool }\end{array}$} & \multirow[t]{2}{*}{ Variables } & \multicolumn{2}{|c|}{$\begin{array}{l}13-72 \text { h Prior to } \\
\text { Hospitalization }\end{array}$} & \multicolumn{2}{|c|}{$\begin{array}{l}\leq 12 \text { h Prior to } \\
\text { Hospitalization }\end{array}$} \\
\hline & & Nonsepsis & Sepsis & Nonsepsis & Sepsis \\
\hline \multirow[t]{3}{*}{ SIRS } & Met screening criteria & $6 \%$ & $10 \%$ & $12 \%$ & $36 \%$ \\
\hline & Sensitivity for sepsis & & $10 \%$ & & $36 \%$ \\
\hline & Specificity for sepsis & & $94 \%$ & & $86 \%$ \\
\hline \multirow[t]{3}{*}{ qSOFA } & Met screening criteria & $4 \%$ & $7 \%$ & $13 \%$ & $27 \%$ \\
\hline & Sensitivity for sepsis & & $7 \%$ & & $27 \%$ \\
\hline & Specificity for sepsis & & $96 \%$ & & $88 \%$ \\
\hline \multirow[t]{3}{*}{$100-100-100$} & Met screening criteria & $16 \%$ & $28 \%$ & $31 \%$ & $79 \%$ \\
\hline & Sensitivity for sepsis & & $28 \%$ & & $79 \%$ \\
\hline & Specificity for sepsis & & $84 \%$ & & $69 \%$ \\
\hline \multirow{3}{*}{$\begin{array}{c}\text { Temperature } \\
\geq 99.0^{\circ} \mathrm{F}\end{array}$} & Met screening criteria & $14 \%$ & $22 \%$ & $15 \%$ & $51 \%$ \\
\hline & Sensitivity for sepsis & & $22 \%$ & & $51 \%$ \\
\hline & Specificity for sepsis & & $86 \%$ & & $85 \%$ \\
\hline \multirow{3}{*}{$\begin{array}{c}\text { Temperature } \\
\geq 100.2^{\circ} \mathrm{F}\end{array}$} & Met screening criteria & $3 \%$ & $9 \%$ & $7 \%$ & $20 \%$ \\
\hline & Sensitivity for sepsis & & $9 \%$ & & $40 \%$ \\
\hline & Specificity for sepsis & & $97 \%$ & & $93 \%$ \\
\hline
\end{tabular}

*Analysis limited to study participants with complete vital sign data; $n=47$ patients with a hospital discharge diagnosis of sepsis and 135 who were hospitalized without sepsis. 
sensitivity above $28 \%$, but all had high specificity ( $84 \%-97 \%)$. In the 12 hours prior to hospitalization, the sensitivity of each improved, with the most sensitive tools being the 100-100-100 criteria (79\%) and an oral temperature $\geq 99.0^{\circ} \mathrm{F}(51 \%)$; and the most specific tools being a temperature $\geq 100.2 \mathrm{~F}$ (93\%), the qSOFA (88\%), the SIRS criteria (86\%), and a temperature $\geq 99.0^{\circ} \mathrm{F}(85 \%)$.

\section{Discussion}

Sepsis is a frequent cause of morbidity and mortality among $\mathrm{NH}$ residents. This study from a sample of $31 \mathrm{NHs}$ with characteristics similar to NHs nationally identified several issues around documentation of active surveillance and medical oversight that may have hindered early detection of sepsis. Particularly noteworthy was the absence of documentation of key status indicators, such as vital signs and cognitive status, in a substantial minority of cases, and the observation that few $\mathrm{NH}$ residents received a medical provider visit prior to hospital transfer. Also noteworthy was the observation that screening criteria for sepsis commonly used in hospital settings appear to perform poorly in the identification of evolving sepsis in this sample.

Our study evaluated 5 potential methods of early screening for sepsis: the SIRS criteria, the qSOFA, the 100-100-100 Early Detection Tool, and temperature thresholds of $99^{\circ} \mathrm{F}$ and $100.2^{\circ} \mathrm{F}$. All had fair to good specificity; however, sensitivity levels were generally low. The relative importance of sensitivity vs specificity of a screening test for sepsis depends on the setting. In the hospital, where suspected sepsis leads to a large number of potentially hazardous responses, such as additional testing, invasive monitoring, and initiation of antibiotics and fluid resuscitation, ${ }^{28,29}$ the specificity of a screening test is especially important. In the NH setting, however, where the goal should be identification of risk and initiation of intensive surveillance, high sensitivity should be preeminent in a screening tool. Here the 100100-100 Early Detection Tool and the threshold of a temperature $\geq 99.0^{\circ} \mathrm{F}$, performed better than the other criteria and screening tools studied. If further research confirms our results, these simple tools might be useful in identifying patients who need intensive monitoring, rapid laboratory studies, and/or an evaluation by a healthcare provider. $^{30,31}$

A prerequisite for effective screening for sepsis in the $\mathrm{NH}$ is documentation of vital signs and cognitive changes that indicate incipient delirium. Table 1 demonstrates that current NH surveillance and documentation of these basic parameters is far from perfect. Indeed, over a quarter of $\mathrm{NH}$ residents lacked documentation of vital signs in the 72 hours prior to hospital transfer. Better surveillance of persons who undergo changes in status is, therefore, an important element of improved detection of early sepsis. How to improve cognitive status documentation, a key element of the qSOFA, is more challenging. The GCS, which the qSOFA recommends, is not appropriate for the $\mathrm{NH}$ setting, both because of its complexity and because it presumes a premorbid normal cognitive status. ${ }^{26}$ Change from baseline is more relevant; however, this too is challenging to measure, because fluctuations in cognitive function are common enough in dementia to not be associated overall with acute events, ${ }^{32}$ and because subsyndromic delirium may be more relevant in screening for sepsis risk but is quite common and heterogeneous in older persons. ${ }^{33}$

Particularly noteworthy was the infrequency in which we found documentation of a visit from a physician, nurse practitioner, or physician assistant during the 72 hours prior to hospital transfer. During the 12 hours prior to transfer, only $19 \%$ of the sepsis admissions and $16 \%$ of the nonsepsis admissions had a medical note or other indication of a provider examination. While it is unrealistic to expect $\mathrm{NH}$ medical staff to have the same on-site presence as their hospital counterparts, ${ }^{34}$ from the standpoint of effective early diagnosis of sepsis, this may be a situation where healthcare providers are indeed "missing in action" and care, therefore, suffers. ${ }^{35}$ A possible solution is telemedicine, if the resources were put in place to make on-call physicians able to have a robust virtual visit to patients with changes in medical status, and if reimbursement were provided at an appropriate level for such services. ${ }^{36}$

An effective $\mathrm{NH}$ sepsis prevention and early detection program will, therefore, require several changes to current care practices. One approach would be to obtain ongoing vital signs on all residents for whom staff notice a status change that could constitute an early sign of infection, and to use the vital signs to screen for sepsis risk employing the 100-100-100 Early Detection Tool and/or a temperature threshold of $99.0^{\circ} \mathrm{F}$ or greater (or 2 standard deviations above that resident's normal temperature) ${ }^{25} \mathrm{NH}$ residents who screen positive would then have an in-person or virtual visit with a medical provider, and would begin scheduled vital sign recordings every 4 hours. Ideally, rapid diagnostic testing and result availability for such markers as the white blood count, serum lactate level, and possibly serum calcitonin would also be put in place, as has been done for portable radiographic testing. A protocol incorporating all of these elements could be expected to reduce hospitalizations for sepsis while improving diagnostic and treatment time for patients with true sepsis. Consequently, further research into practice changes that would make this capacity possible should be considered a priority.

Our study has several limitations. Because the research was conducted using an institutional review board approved waiver of informed consent, our study staff did not review all hospital records but rather depended on what hospital records were returned to the $\mathrm{NH}$. As a result, we excluded from our study the $20 \%$ of $\mathrm{NH}$ residents who were hospitalized and failed to return to the $\mathrm{NH}$, either because of death or discharge to a different setting. Furthermore, our ability to determine whether study participants met SOFA criteria was limited to discharge summaries and, if available, admission records. So, while only two-thirds of study participants met SOFA criteria based on our data collection, more might have met SOFA criteria if complete records had been reviewed, and, as in many hospital settings, our diagnostic standard for sepsis (the hospital discharge summary) may have lacked diagnostic specificity. ${ }^{37}$

\section{Conclusions}

This study found that a substantial minority of NH residents who were subsequently hospitalized for sepsis did not have vital signs documented prior to hospital transfer, and that the majority were not seen by a physician, nurse practitioner, or physician assistant prior to transfer. It also found that no tool adequately screens for early sepsis in the $\mathrm{NH}$ population but that several show some promise. Most importantly, it demonstrated that NHs need better systems to monitor $\mathrm{NH}$ residents whose status is changing, and to present that information to medical providers in real time, either through rapid medical response programs or telemetry. Finally, the poor performance of all screening tests means that medical and nursing staff must not overinterpret or overreact. As a result, $\mathrm{NH}$ medical staff will have to continue using clinical judgment and what tools are available in an attempt to negotiate between the Scylla of underdiagnosis and the Charybdis of overtreatment.

\section{References}

1. Harris-Kojetin L, Sengupta M, Park-Lee E, et al. Long-term care providers and services users in the United States: Data from the National Study of Long-Term Care Providers, 2013-2014. Vital Health Stat 20 2016;3:1-105.

2. Wang HE, Shah MN, Allman RM, et al. Emergency department visits by nursing home residents in the United States. J Am Geriatr Soc 2011;59:1864-1872.

3. Ginde AA, Moss M, Shapiro NI, et al. Impact of older age and nursing home residence on clinical outcomes of US emergency department visits for severe sepsis. J Crit Care 2013;28:606-611. 
4. Marwick C, Santiago VH, McCowan C, et al. Community acquired infections in older patients admitted to the hospital form care homes versus the community: Cohort study of microbiology and outcomes. BMC Geriatr 2013;13:12.

5. Ahmed AA, Hays CI, Lui B, et al. Predictors of in-hospital mortality among hospitalized nursing home residents: An analysis of the National Hospital Discharge Surveys 2005-2006. J Am Med Dir Assoc 2010;11:52-58.

6. Iwashyna TJ, Ely EW, Smith DM, et al. Long-term cognitive impairment and functional disability among survivors of severe sepsis. JAMA 2010;304: 1787-1794.

7. Levy MM, Fink MP, Marshall JC, et al. 2001 SCCM/ESICM/ACCP/ATS/SIS International Sepsis Definitions Conference. Crit Care Med 2003:31:1250-1256.

8. Vincent JL, Opal SM, Marshall JC, et al. Sepsis definitions: Time for change. Lancet 2013;381:774-775.

9. Nguyen HB, Corbett SW Steele R, et al. Implementation of a bundle of quality indicators for the early management of severe sepsis and septic shock is associated with decreased mortality. Crit Care Med 2007;35:1105-1112.

10. Rhee C, Gohil S, Klompas M. Regulatory mandates for sepsis care-reasons for caution. N Engl J Med 2014;370:1673-1676.

11. Singer $M$, Deutschman CS, Seymour CW, et al. The third international consensus definitions for sepsis and septic shock (Sepsis-3). JAMA 2016;315: $801-810$.

12. Dorsett M, Kroll M, Smith CS, et al. qSOFA Has poor sensitivity for prehospital identification of severe sepsis and septic shock. Prehosp Emerg Care 2017;21: 489-497.

13. Minnesota Hospital Association [Internet]. St. Paul, MN. c2017. Available at: http://www.mnhospitals.org/quality-patient-safety/quality-patient-safetyinitiatives/sepsis-and-septic-shock\#/videos/list. Accessed December 3, 2017.

14. Minnesota Hospital Association [Internet]. St. Paul, MN. c2017. Available at: http://www.mnhospitals.org/Portals/0/Documents/ptsafety/SeeingSepsisL TC/1.\%20Seeing\%20Sepsis\%20-\%20LTC\%20Poster.pdf. Accessed December 3, 2017.

15. Gorzoni ML, Pires SL. Deaths in nursing homes. Rev Assoc Med Bras 2011;57: $327-331$.

16. Khayr WF, CarMichael MJ, Dubanowich CS, et al. Bacteremia in Veterans Administration nursing home patients. Am J Ther 2004;11:251-257.

17. Rowe T, Araujo K, Van Ness P, et al. Outcomes of older adults with sepsis at admission to an intensive care unit. Open Forum Infect Dis 2016;3:ofw010.

18. Herring AR, Williamson JC. Principles of antimicrobial use in older adults. Clin Geriatr Med 2007;23:481-497.

19. Weber S, Mawdsley E, Kaye D. Antibacterial agents in the elderly. Infect Dis Clin North Am 2009;23:881-898.

20. Venkatachalam I, Yang HL, Fisher D, et al. Multidrug-resistance gram-negative bloodstream infections among residents of long-term care facilities. Infect Control Hosp Epidemiol 2014;35:519-526.

21. Pereira R, Oliveira S, Almeida A. Nursing home-acquired pneumonia presenting at the emergency department. Intern Emerg Med 2016;11:999-1004.
22. Medicare.gov. Nursing Home Compare. Medicare.gov. 2016. Available at: https://www.medicare.gov/NursingHomeCompare/search.html. Accessed August 31, 2015.

23. SAS Institute Inc. Base SAS 9.4 Procedures Guide. Cary, NC: SAS Institute Inc; 2013.

24. Fever Temperatures: Accuracy and Comparison-Topic Overview. WebMD. Available at: 2016. http://www.webmd.com/children/tc/fever-temperaturesaccuracy-and-comparison-topic-overview. Accessed November 27, 2017.

25. Sloane PD, Kistler C, Mitchell CM, et al. Role of body temperature in diagnosing bacterial infection in nursing home residents. I Am Geriatr Soc 2014;62 135-140.

26. High KP, Bradley SF, Gravenstein S, et al. Infectious Diseases Society of America. Clinical practice guideline for the evaluation of fever and infection in older adult residents of long-term care facilities: 2008 update by the Infectious Diseases Society of America. J Am Geriatr Soc 2009;57:375-394.

27. Teasdale G, Maas A, Lecky F, et al. The Glasgow Coma Scale at 40 years: Standing the test of time. Lancet Neurol 2014:13:844-854.

28. Dellinger RP, Levy MM, Rhodes A, et al. Surviving sepsis campaign: International guidelines for management of severe sepsis and septic shock: 2012. Crit Care Med 2013;41:580-637.

29. Turi SK, Von Ah D. Implementation of early goal-directed therapy for septic patients in the emergency department: A review of the literature. J Emerg Nurs 2013;39:13-19.

30. INTERACT Guidance on Possible Sepsis. Available at: http://www.pathwayinteract.com/wp-content/uploads/2017/11/INTERACT-Guidance-on-PossibleSepsis-November-8-2017.pdf. Accessed December 8, 2017.

31. Schuetz P, Wirz Y, Sager R, et al. Procalcitonin to initiate or discontinue antibiotics in acute respiratory tract infections. Cochrane Database Syst Rev 2017; 10:CD007498.

32. Sloane PD, Schifeling $\mathrm{CH}$, Beeber AS, et al. New or worsening symptoms and signs in community-dwelling persons with dementia: Incidence and relation to use of acute medical services. J Am Geriatr Soc 2017;65:808-814.

33. Cole MG, Ciampi A, Belzile E, et al. Subsyndromal delirium in older people: A systematic review of frequency, risk factors, course and outcomes. Int J Geriatr Psychiatry 2013;28:771-780.

34. Katz PR, Karuza J. Physician practice in the nursing home: Missing in action or misunderstood. J Am Geriatr Soc 2005:53:1826-1828.

35. Shield RR, Wetle T, Teno J, et al. Physicians "missing in action": Family perspectives on physician and staffing problems in end-of-life care in the nursing home. J Am Geriatr Soc 2005;53:1651-1657.

36. Grabowski DC, O'Malley AJ. Use of telemedicine can reduce hospitalizations of nursing home residents and generate savings for Medicare. Health Aff (Millwood) 2014;33:244-250.

37. Burston J, Adhikari S, Hayen A, et al. A role for antimicrobial stewardship in clinical sepsis pathways: A prospective interventional study. Infect Control Hosp Epidemiol 2017;38:1032-1038. 
Appendix

Spreadsheet of Data for Calculating SOFA Score Among Sepsis Participants With Hospital Discharge Summaries $(\mathrm{n}=54)$

\begin{tabular}{|c|c|c|c|c|c|c|c|c|c|c|c|c|c|c|c|c|}
\hline ID & $\begin{array}{l}\mathrm{PaO}_{2} / \\
\mathrm{FiO}_{2}\end{array}$ & $\begin{array}{l}\text { Respir- } \\
\text { ation } \\
\text { Score }\end{array}$ & $\begin{array}{l}\text { Highest } \\
\text { Bilirubin }\end{array}$ & $\begin{array}{l}\text { Liver } \\
\text { Score }\end{array}$ & $\begin{array}{l}\text { Mean } \\
\text { Arterial } \\
\text { Pres-sure }\end{array}$ & $\begin{array}{l}\text { Cardio- } \\
\text { vascular } \\
\text { Score }\end{array}$ & $\begin{array}{l}\text { Lowest } \\
\text { Platelet } \\
\text { Count }\end{array}$ & $\begin{array}{l}\text { Coagulation } \\
\text { score }\end{array}$ & GCS & MSI & $\begin{array}{l}\text { CNS Score } \\
\text { Using } \\
\text { GCS } \\
\text { Only }\end{array}$ & $\begin{array}{l}\text { Adjusted CNS } \\
\text { Score with MSI }\end{array}$ & Creatinine & $\begin{array}{l}\text { Renal } \\
\text { Score }\end{array}$ & $\begin{array}{l}\text { Rough } \\
\text { SOFA } \\
\text { Score } \\
\text { with MSI }\end{array}$ & $\begin{array}{l}\text { Rough SOFA } \\
\text { Score without } \\
\text { MSI }^{\ddagger}\end{array}$ \\
\hline 12221 & & & 0.54 & 0 & & & 116000 & 1 & & & & & 0.6 & 0 & 1 & 1 \\
\hline 14208 & 214 & 2 & 1 & 0 & & & 179000 & 0 & & Yes & & 1 & 1.98 & 2 & 5 & 4 \\
\hline 14216 & & & 0.3 & 0 & & & 185000 & 0 & & Yes & & 1 & 0.77 & 0 & 1 & 0 \\
\hline 15221 & 329 & 1 & & & 66 & 1 & 288000 & 0 & & & & & 0.6 & 0 & 2 & 2 \\
\hline 15222 & 329 & 1 & 0.19 & 0 & 87 & 0 & 475000 & 0 & & & & & 0.6 & 0 & 1 & 1 \\
\hline 16137 & & & & & & & 432000 & 0 & & Yes & & 1 & 0.56 & 0 & 1 & 0 \\
\hline 20127 & & & & & & & 262000 & 0 & & Yes & & 1 & 0.9 & 0 & 1 & 0 \\
\hline 20221 & 410 & 0 & & & 105 & 0 & 168000 & 0 & & Yes & & 1 & 1.4 & 1 & 2 & 1 \\
\hline 20226 & 410 & 0 & & & & & 256000 & 0 & & Yes & & 1 & 2.2 & 2 & 3 & 2 \\
\hline 20229 & 329 & 1 & 0.6 & 0 & & & 183000 & 0 & & Yes & & 1 & 1.4 & 1 & 3 & 2 \\
\hline 21207 & 290 & 2 & & & & & 217000 & 0 & & & & & 2.82 & 2 & 4 & 4 \\
\hline $21208^{*}$ & & & 0.9 & 0 & 67 & 2 & 205000 & 0 & & Yes & & 1 & 4.51 & 3 & 6 & 5 \\
\hline 21211 & & & & & 86 & 0 & 453000 & 0 & & & & & 2.8 & 2 & 2 & 2 \\
\hline 21215 & & & & & 76 & 0 & 151000 & 0 & & & & & 1.02 & 0 & 0 & 0 \\
\hline 22222 & 282 & 2 & 0.5 & 0 & 110 & 0 & 145000 & 1 & & Yes & & 1 & 0.93 & 0 & 4 & 3 \\
\hline 22223 & & & & & & & & & & & & & & & 0 & 0 \\
\hline 22228 & 192 & 3 & & & 117 & 0 & 127000 & 1 & & No & & 0 & 0.65 & 0 & 4 & 4 \\
\hline 24201 & 690 & 0 & & & 76 & 0 & 623000 & 0 & & Yes & & 1 & 2.9 & 2 & 3 & 2 \\
\hline 24204 & 138 & 3 & & & 76 & 0 & 161000 & 0 & & Yes & & 1 & 1.4 & 1 & 5 & 4 \\
\hline 24206 & & & 0.3 & 0 & & & 170000 & 0 & & Yes & & 1 & 1.4 & 1 & 2 & 1 \\
\hline 25227 & 533 & 0 & 0.84 & 0 & 77 & 0 & 144000 & 1 & & Yes & & 1 & 1.73 & 1 & 3 & 2 \\
\hline 27207 & & & 0.4 & 0 & 88 & 0 & 206000 & 0 & 14 & Yes & 1 & 1 & 0.59 & 0 & 1 & 1 \\
\hline 28021 & & & & & 65 & 1 & 384000 & 0 & & Yes & & 1 & 0.8 & 0 & 2 & 1 \\
\hline 28022 & & & & & & & 232000 & 0 & & & & & 2.4 & 2 & 2 & 2 \\
\hline 28024 & & & & & 72 & 0 & 316000 & 0 & & & & & 1.5 & 1 & 1 & 1 \\
\hline 28234 & 690 & 0 & & & 66 & 1 & 401000 & 0 & & Yes & & 1 & 1.8 & 1 & 3 & 2 \\
\hline 28237 & & & 0.8 & 0 & & & 377000 & 0 & & Yes & & 1 & 1.5 & 1 & 2 & 1 \\
\hline 30202 & 348 & 1 & 0.7 & 0 & 86 & 0 & 218000 & 0 & & Yes & & 1 & 1.5 & 1 & 3 & 2 \\
\hline 30207 & & & 0.2 & 0 & 97 & 0 & 246000 & 0 & & Yes & & 1 & 2.6 & 2 & 3 & 2 \\
\hline 32102 & & & & & 75 & 0 & 109000 & 1 & & & & & & & 1 & 1 \\
\hline 32227 & 203 & 2 & 0.6 & 0 & 68 & 1 & 332000 & 0 & & & & & 1.27 & 1 & 4 & 4 \\
\hline 33227 & 261 & 2 & & & 93 & 0 & 361000 & 0 & & Yes & & 1 & 1.03 & 0 & 3 & 2 \\
\hline 33229 & 282 & 2 & 0.7 & 0 & 87 & 0 & 118000 & 1 & & Yes & & 1 & 0.41 & 0 & 4 & 3 \\
\hline 33231 & 307 & 1 & 0.9 & 0 & 71 & 0 & 181000 & 0 & & & & & 0.59 & 0 & 1 & 1 \\
\hline 33235 & & & & & 68 & 1 & 155000 & 0 & & Yes & & 1 & 1.14 & 0 & 2 & 1 \\
\hline 34005 & & & 0.6 & 0 & 75 & 0 & 299000 & 0 & & Yes & & 1 & 1.04 & 0 & 1 & 0 \\
\hline $35114^{\dagger}$ & & & 0.8 & 0 & 71 & 0 & 245000 & 0 & & Yes & & 1 & 2.7 & 2 & 3 & 2 \\
\hline 35207 & 690 & 0 & & & 109 & 0 & 712000 & 0 & & & & & 0.88 & 0 & 0 & 0 \\
\hline 36205 & 269 & 2 & & & 79 & 0 & 296000 & 0 & & & & & 1.23 & 1 & 3 & 3 \\
\hline 36220 & 533 & 0 & & & 66 & 1 & 82000 & 2 & & No & & 0 & 1.25 & 1 & 4 & 4 \\
\hline 38118 & & & & & & & 284000 & 0 & & Yes & & 1 & 0.72 & 0 & 1 & 0 \\
\hline 39107 & & & 1.1 & 0 & 60 & 1 & 174000 & 0 & & Yes & & 1 & 1.4 & 1 & 3 & 2 \\
\hline $39215^{\dagger}$ & 210 & 2 & & & 58 & 1 & & & & Yes & & 1 & 0.8 & 0 & 4 & 3 \\
\hline 39219 & 376 & 1 & 0.5 & 0 & 66 & 1 & 535000 & 0 & & Yes & & 1 & 1.3 & 1 & 4 & 3 \\
\hline 39221 & 392 & 1 & & & 57 & 1 & 453000 & 0 & & No & & 0 & 1 & 0 & 2 & 2 \\
\hline 40207 & & & 0.28 & 0 & 97 & 0 & 278000 & 0 & & Yes & & 1 & 1.1 & 0 & 1 & 0 \\
\hline $44015^{\dagger}$ & 232 & 2 & & & 64 & 1 & 325000 & 0 & & Yes & & 1 & 0.69 & 0 & 4 & 3 \\
\hline 44202 & & & & & 115 & 0 & 194000 & 0 & & No & & 0 & 1.32 & 1 & 1 & 1 \\
\hline 44204 & 376 & 1 & 0.4 & 0 & 104 & 0 & 295000 & 0 & & & & & 0.46 & 0 & 1 & 1 \\
\hline 44209 & 690 & 0 & 0.4 & 0 & 100 & 0 & 248000 & 0 & & Yes & & 1 & 1.1 & 0 & 1 & 0 \\
\hline 47005 & 329 & 1 & & & 90 & 0 & 124000 & 1 & & Yes & & 1 & 2.9 & 2 & 5 & 4 \\
\hline 47008 & 376 & 1 & & & 108 & 0 & 349000 & 0 & & & & & 1.4 & 1 & 2 & 2 \\
\hline 47237 & & & & & & & 273000 & 0 & & No & & 0 & 0.6 & 0 & 0 & 0 \\
\hline 49011 & 247 & 2 & 0.5 & 0 & 89 & 0 & 171000 & 0 & & No & & 0 & 0.82 & 0 & 2 & 2 \\
\hline
\end{tabular}

CNS, central nervous system; ID, identification; MSI, mental status impairment.

* Received dopamine.

†Received norepinephrine.

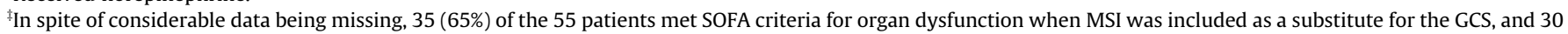
(56\%) met SOFA criteria for organ dysfunction. 